\title{
Involvement of lipid rafts in the localization and dysfunction effect of the antitumor ether phospholipid edelfosine in mitochondria
}

\author{
F Mollinedo ${ }^{\star, 1}$, M Fernández $^{2}$, V Hornillos ${ }^{3}$, J Delgado ${ }^{3}$, F Amat-Guerri $^{3}$, AU Acuña ${ }^{4}$, T Nieto-Miguel ${ }^{1}$, JA Villa-Pulgarín ${ }^{1,5}$, \\ C González-García ${ }^{6}$, V Ceña ${ }^{7,8}$ and C Gajate ${ }^{\star, 1}$
}

Lipid rafts and mitochondria are promising targets in cancer therapy. The synthetic antitumor alkyl-lysophospholipid analog edelfosine (1-0-octadecyl-2-0-methyl-rac-glycero-3-phosphocholine) has been reported to target lipid rafts. Here, we have found that edelfosine induced loss of mitochondrial membrane potential and apoptosis in human cervical carcinoma HeLa cells, both responses being abrogated by $\mathrm{Bcl}-\mathrm{x}_{\mathrm{L}}$ overexpression. We synthesized a number of new fluorescent edelfosine analogs, which preserved the proapoptotic activity of the parent drug, and colocalized with mitochondria in HeLa cells. Edelfosine induced swelling in isolated mitochondria, indicating an increase in mitochondrial membrane permeability. This mitochondrial swelling was independent of reactive oxygen species generation. A structurally related inactive analog was unable to promote mitochondrial swelling, highlighting the importance of edelfosine molecular structure in its effect on mitochondria. Raft disruption inhibited mitochondrial localization of the drug in cells and edelfosine-induced swelling in isolated mitochondria. Edelfosine promoted a redistribution of lipid rafts from the plasma membrane to mitochondria, suggesting a raft-mediated link between plasma membrane and mitochondria. Our data suggest that direct interaction of edelfosine with mitochondria eventually leads to mitochondrial dysfunction and apoptosis. These observations unveil a new framework in cancer chemotherapy that involves a link between lipid rafts and mitochondria in the mechanism of action of an antitumor drug, thus opening new avenues for cancer treatment.

Cell Death and Disease (2011) 2, e158; doi:10.1038/cddis.2011.41; published online 19 May 2011

Subject Category: Cancer

Mitochondria are central hubs for intrinsic apoptotic pathways that are activated by cellular stress and injury, playing a critical role in physiological and drug-induced apoptosis. Mitochondria contain a number of proapoptotic proteins, which are released following the formation in the mitochondrial membrane of the so-called permeability transition pore (PTP), ${ }^{1}$ thus leading to the generation of the apoptosome and the triggering of the mitochondrial intrinsic pathway of cell death. Recently, mitochondria in cancer cells have emerged as the Achilles' heel for tumor destruction. Anticancer agents specifically targeting cancer cell mitochondria, referred to as 'mitocans', act by destabilizing these organelles, unleashing their apoptogenic potential and resulting in the efficient death of malignant cells. ${ }^{2}$
Edelfosine (1-O-octadecyl-2-O-methyl-rac-glycero-3-phosphocholine) is the prototype compound of a family of promising synthetic antitumor drugs collectively known as alkyl-lysophospholipid analogs or antitumor ether lipids. ${ }^{3-5}$ This group of compounds also includes miltefosine, marketed under the trade name of Miltex (Baxter Oncology $\mathrm{GmbH}$, Halle/Westfalen, Germany) as a topical drug for the palliative treatment of cutaneous metastases from breast cancer, and perifosine, currently in phase II clinical trials. ${ }^{6}$ Edelfosine shows affinity for cholesterol, ${ }^{7,8}$ and has been reported to kill a wide variety of tumor cells through its accumulation in lipid rafts, ${ }^{9-12}$ which are membrane microdomains enriched in cholesterol and sphingolipids. Edelfosine treatment led to alterations in the biophysical features as well as in the protein

\footnotetext{
${ }^{1}$ Centro de Investigación del Cáncer, Instituto de Biología Molecular y Celular del Cáncer, CSIC-Universidad de Salamanca, Campus Miguel de Unamuno, E-37007 Salamanca, Spain; ' ${ }^{2}$ Laboratorio de Neurofisiología y Plasticidad Sináptica, Instituto de Investigación en Discapacidades Neurológicas (IDINE), Universidad de CastillaLa Mancha, E-02006 Albacete, Spain; ${ }^{3}$ Instituto de Química Orgánica General, CSIC, Juan de la Cierva 3, E-28006 Madrid, Spain; ${ }^{4}$ Instituto de Química Física Rocasolano, CSIC, Serrano 119, E-28006 Madrid, Spain; ${ }^{5}$ Apointech, Centro Hispano-Luso de Investigaciones Agrarias (CIALE), Parque Científico de la Universidad de Salamanca, C/ Rio Duero 12, E-37185 Villamayor, Salamanca, Spain; ${ }^{6}$ Departamento de Ciencias Médicas, Facultad de Medicina, Universidad de Castilla-La Mancha, E-02006 Albacete, Spain; ${ }^{7}$ Unidad Asociada 'Neurodeath', UCLM-CSIC, Universidad de Castilla-La Mancha, E-02006 Albacete, Spain and ${ }^{8}$ CIBER de Enfermedades Neurodegenerativas, Instituto de Salud Carlos III, Sinesio Delgado 6, E-28029 Madrid, Spain

${ }^{*}$ Corresponding authors: F Mollinedo and C Gajate, Centro de Investigación del Cáncer, Instituto de Biología Molecular y Celular del Cáncer, CSIC-Universidad de Salamanca, Campus Miguel de Unamuno, Salamanca E-37007, Spain. Tel: + 34 923-294806; Fax: + 34 923-294795; E-mail: fmollin@ usal.es and cgajate@ usal.es Keywords: mitochondria; lipid rafts; ether phospholipid; edelfosine; apoptosis; cancer therapy

Abbreviations: BDP, BODIPY or borondifluorodipyrromethene; CsA, cyclosporin A; DiOC 6 (3), 3,3'-dihexyloxacarbocyanine iodide; Et-BDP-ET, 1-O-(11'-(6" ${ }^{\prime \prime}$-ethyl$1^{\prime \prime}, 3^{\prime \prime}, 5^{\prime \prime}, 7^{\prime \prime}$-tetramethyl-4", $4^{\prime \prime}$-difluoro-4"-bora-3a",4a"-diaza-s-indacen-2" -yl)undecyl)-2-O-methyl-rac-glycero-3-phosphocholine; ET-18-OH, 1-O-octadecyl-rac-gly-

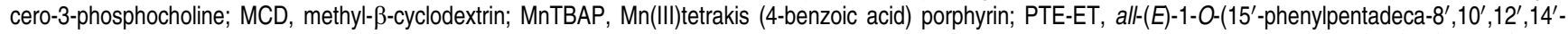

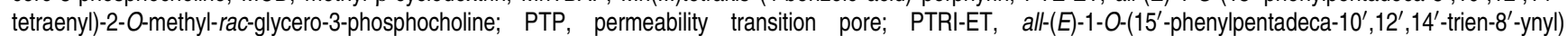
-2-O-methyl-rac-glycero-3-phosphocholine; ROS, reactive oxygen species; Yn-BDP-ET, 1-O-(13'-(1", $3^{\prime \prime}, 5^{\prime \prime}, 7^{\prime \prime}$-tetramethyl-4", $4^{\prime \prime}$-difluoro-4" -bora-3a", 4a"-diaza-sindacen-2" -yl)tridec-12'-ynyl)-2-O-methyl-rac-glycero-3-phosphocholine; $\Delta \Psi_{\mathrm{m}}$, mitochondrial transmembrane potential

Received 20.1.11; revised 04.4.11; accepted 12.4.11; Edited by P Salomoni
} 
and lipid composition of rafts. ${ }^{7,10,13,14}$ Edelfosine has also been found to accumulate in the endoplasmic reticulum of solid tumor cells, ${ }^{15}$ promoting an endoplasmic reticulum stress response. ${ }^{16}$ Yet, irrespective of the edelfosine action on lipid rafts or endoplasmic reticulum, the apoptotic response triggered by this drug requires the participation of mitochondrial-mediated signaling, this latter acting as the critical event that leads eventually to the demise of the tumor cell. ${ }^{16,17}$ Edelfosineinduced apoptosis involves disruption of the mitochondrial transmembrane potential $\left(\Delta \Psi_{\mathrm{m}}\right)$ and release of mitochondrial cytochrome $c$ to the cytosol in a number of hematological cancer cells. ${ }^{17,18}$ Because both lipid rafts and mitochondria have been involved in the apoptotic response induced by edelfosine, we analyzed whether edelfosine interacted directly with mitochondria and whether lipid rafts were implicated in a mitochondrial-dependent action of the antitumor drug.

\section{Results}

Edelfosine induces apoptosis in HeLa cells through a mitochondrial-mediated process. We found that edelfosine induced disruption of $\Delta \Psi_{\mathrm{m}}$ and apoptosis in human cervix epithelioid carcinoma HeLa cells in a timedependent manner, assessed through 3,3'-dihexyloxacarbocyanine iodide $\left(\mathrm{DiOC}_{6}(3)\right)$ fluorescence and cell cycle analysis (hypodiploidy) by flow cytometry (Figure 1a). Edelfosine induced $\Delta \Psi_{\mathrm{m}}$ loss before the onset of apoptosis (Figure 1a). Ectopic overexpression of $\mathrm{Bcl}-\mathrm{x}_{\mathrm{L}}$ by gene transfer in HeLa cells ${ }^{16}$ prevented both $\Delta \Psi_{\mathrm{m}}$ disruption and DNA fragmentation (Figure 1b). These results indicate the involvement of mitochondria in edelfosine-induced apoptosis in HeLa cells.

Synthesis of new fluorescent analogs of edelfosine preserving the parent drug's proapoptotic activity. To visualize the subcellular localization of edelfosine in HeLa cells, we used fluorescent analogs of the alkyl ether phospholipid. Fluorescent analogs were designed in such a way that the amphipathic properties and the main structural motifs of the alkyl ether lipid ${ }^{3}$ were preserved (Supplementary Information). High fluorescence yield and good photostability were also sought for, whenever possible. Thus, we produced first a family of emitting analogs in which a fragment of the original linear polymethylene chain was replaced by a conjugated all-(E)-phenyltetraene, or a conjugated all-(E)-phenyltrienyne chromophore, to yield PTE-ET

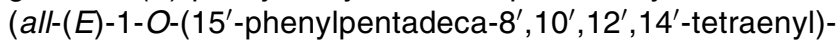
2-O-methyl-rac-glycero-3-phosphocholine) and PTRI-ET (all-(E)-1-O-(15'-phenylpentadeca-10',12',14'-trien-8'-ynyl)-2O-methyl-rac-glycero-3-phosphocholine) analogs, respectively (Figure 2). The proapoptotic activity of these blue-emitting alkyl lipids was similar to that of the parent compound (Figure 3), as assessed by their ability to induce apoptosis in HeLa cells, although their photostability under the intense near-UV laser excitation of the microscope was poor (Supplementary Information). Both fluorescence yield and resistance to photodegradation were largely improved in the second class of analogs synthesized here, which showed convenient excitation and emission spectra in the visible
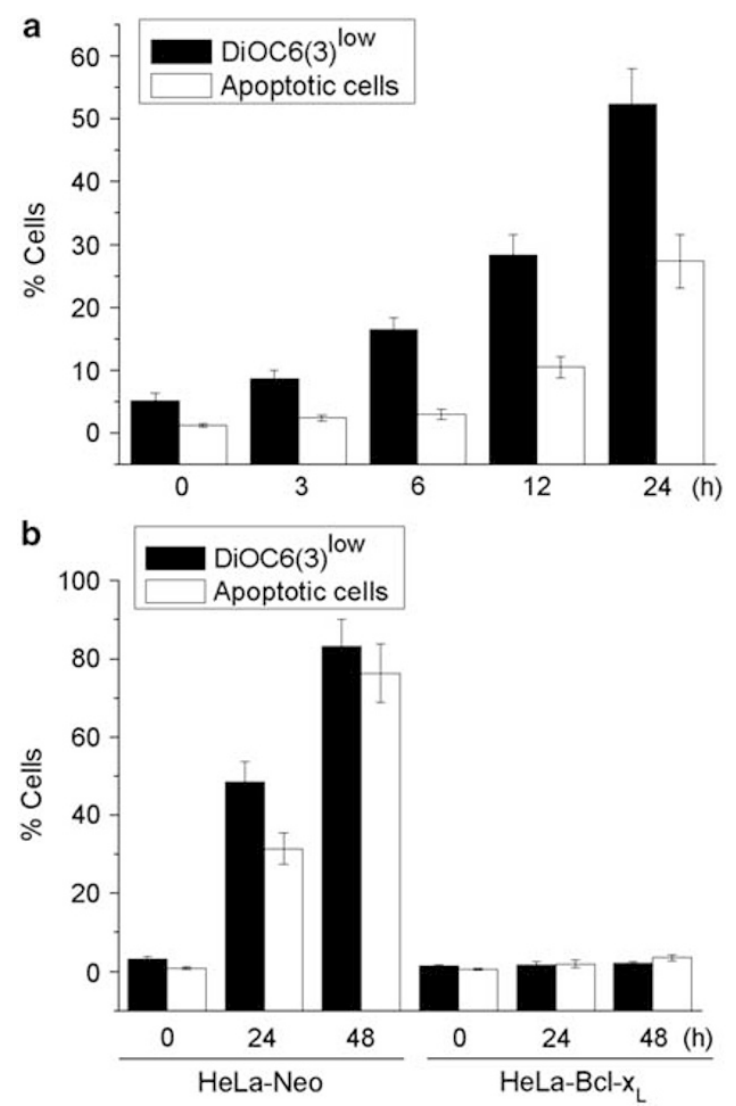

Figure 1 Involvement of mitochondria in edelfosine-induced apoptosis in HeLa cells. (a) Time course of the effects of edelfosine on $\Delta \Psi_{\mathrm{m}}$ disruption and induction of apoptosis in HeLa cells. Cells were treated with $10 \mu \mathrm{M}$ edelfosine for the indicated times, and percentages of cells with disrupted $\Delta \Psi_{\mathrm{m}}\left(\mathrm{DioC}_{6}(3)^{\mathrm{low}}\right)$ and showing DNA degradation (hypodiploidy in cell cycle analysis) were measured by flow cytometry, as described in the Materials and Methods section. (b) Prevention of edelfosineinduced $\Delta \Psi_{\mathrm{m}}$ disruption and apoptosis by overexpression of $\mathrm{Bcl}-\mathrm{x}_{\mathrm{L}}$. HeLa cells transfected with empty vector (HeLa-neo) and $B c l-x_{L}\left(H e L a-B c l-x_{L}\right.$ ) were treated with $10 \mu \mathrm{M}$ edelfosine for the indicated times, and percentages of cells with disrupted $\Delta \Psi_{\mathrm{m}}\left(\mathrm{DioC}_{6}(3)^{\text {low }}\right)$ and showing DNA degradation (hypodiploidy in cell cycle analysis) were measured as above. Data are means \pm S.D. of three independent experiments

range. This was made possible by attaching a 2-substituted borondifluorodipyrromethene (BODIPY, BDP) fluorophore to the alkyl chain of edelfosine (Supplementary Information), to

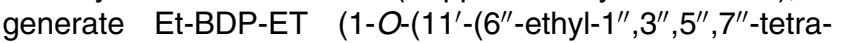
methyl-4" ,4"-difluoro-4" -bora-3a", $4 a^{\prime \prime}$-diaza-s-indacen-2" -yl) undecyl)-2-O-methyl-rac-glycero-3-phosphocholine) and Yn-BDP-ET (1-O-(13'-(1", $3^{\prime \prime}, 5^{\prime \prime}, 7^{\prime \prime}$-tetramethyl-4" $4^{\prime \prime} 4^{\prime \prime}$-difluoro$4^{\prime \prime}$-bora-3a", $4 a^{\prime \prime}$-diaza-s-indacen-2" -yl)tridec-12'-ynyl)-2-Omethyl-rac-glycero-3-phosphocholine) analogs (Figure 2). In spite of this substantial change in the lipid structure, these BODIPY analogs also showed a high proapoptotic activity, similar to that of the parent drug edelfosine (Figure 3). The synthesis and characterization of the new edelfosine analogs, which are structurally related to physiological lysophosphatidylcholine molecule (Figure 2), are described in the Supplementary Information.

Fluorescent edelfosine analogs colocalize with mitochondria in HeLa cells. The edelfosine fluorescent 
<smiles>CC(C)(C)OCC(O)COP</smiles>

edelfosine (EDLF or ET): $\mathrm{R}^{1}=\mathrm{Me}$ $\mathrm{ET}-18-\mathrm{OH}: \mathrm{R}^{1}=\mathrm{H}$<smiles>[R]OCC(O)COC([R])=O</smiles>

LysoPC

( $R^{2}=$ acyl group chain)<smiles>COC(COCC(C)(C)C)COC(C)(C)C=C(C)c1ccccc1</smiles>

PTE-ET<smiles>COC(COP)COC(C)(C)C#CC(C)(C)C#CC(C)(C)C</smiles><smiles></smiles><smiles></smiles>

Yn-BDP-ET<smiles></smiles>

Figure 2 Chemical structures of edelfosine (EDLF, ET), the structurally related inactive analog ET-18-OH, the related physiological compound lysophosphatidylcholine (LysoPC) and the fluorescent analogs of edelfosine PTE-ET, PTRI-ET, Et-BDP-ET and Yn-BDP-ET. The chemical structure of phosphatidylcholine (PC) is also shown

analog PTE-ET (Figure 2) has been shown to behave as a bona fide analog to analyze edelfosine localization in the cell. $^{10,15}$ We found that PTE-ET colocalized with mitochondria in HeLa cells (Figure 4), which showed a large cytoplasm/nucleus ratio, thus allowing a good definition of intracellular structures. Mitochondria were identified by using the cell-permeant mitochondrion selective probe MitoTracker (Molecular Probes, Eugene, OR, USA). As shown in Figure 4, colocalization of edelfosine and mitochondria was detected by the onset of apoptosis (see Figures 1 and 4). PTE-edelfosine fluorescence was weak and rapidly bleached, thus preventing the use of confocal

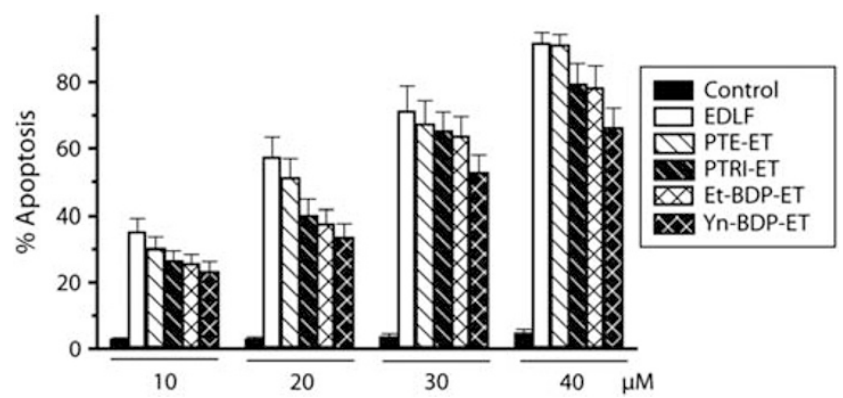

Figure 3 Fluorescent analogs preserve the proapoptotic activity of edelfosine. HeLa cells were treated with the parent drug edelfosine (EDLF) or with the distinct fluorescent analogs PTE-ET, PTRI-ET, Et-BDP-ET and Yn-BDP-ET at the indicated concentrations for $24 \mathrm{~h}$, and apoptosis was then quantitated as percentage of cells in the sub-G1 region (hypodiploidy) in cell cycle analysis by flow cytometry. Untreated control cells were run in parallel. Data are means \pm S.D. of four independent experiments

microscopy analysis, ${ }^{10,15}$ but the modest blue fluorescence of this compound allowed us to identify the subcellular localization of edelfosine. The fluorescent PTRI-ET analog also colocalized with mitochondria (Figure 5). Both PTE-ET and PTRI-ET share analogous fluorescence traits with a rather poor fluorescence yield and photostability under the intense near-UV laser excitation of the microscope (Supplementary Information). To improve resolution to gain a further insight into the subcellular localization of edelfosine, we used the novel Et-BDP-ET and Yn-BDP-ET analogs (Figure 2), which allowed us to visualize the subcellular localization of the fluorescent compounds in HeLa cells through confocal microscopy, as the fluorescent signal was more stable. This second class of edelfosine analogs, EtBDP-ET and Yn-BDP-ET (Figure 2), containing a BODIPY fluorophore attached to the alkyl chain of edelfosine, had a higher fluorescence yield and resistance to photodegradation than the above PTE-ET and PTRI-ET (Supplementary Information). By using the fluorescent edelfosine analogs Et-BDP-ET and Yn-BDP-ET, we found a remarkable colocalization between these compounds and mitochondria, which were detected as a branched filament network (Figure 5). Incorporation of the above fluorescent analogs in HeLa cells was blocked by adding the parent drug edelfosine (data not shown), further supporting the use of the above compounds as reliable fluorescent analogs of edelfosine for in situ subcellular localization studies of the drug.

Furthermore, the location of edelfosine in mitochondria was mediated by lipid rafts, because when HeLa cells were treated with $2.5 \mathrm{mg} / \mathrm{ml}$ methyl- $\beta$-cyclodextrin (MCD) to deplete cholesterol and disrupt lipid rafts, ${ }^{14,17,19}$ edelfosine localization in mitochondria was prevented (data not shown).

Edelfosine affects isolated mitochondria. As the above results suggested that edelfosine interacted with mitochondria in HeLa cells, we analyzed whether this drug was able to affect isolated mitochondria. We examined whether edelfosine might act as an inducer of the PTP opening in isolated liver mitochondria. As opening of the PTP is followed by an increase of inner membrane permeability to solutes with a molecular mass of $<1500 \mathrm{Da}$, the resulting increase in mitochondrial volume (swelling) can be monitored by a 


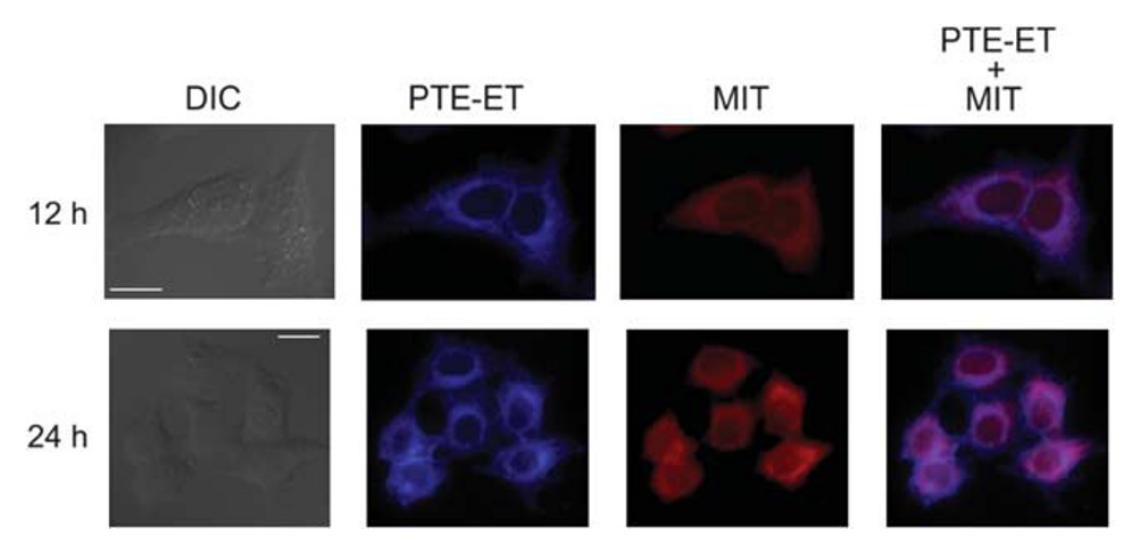

Figure 4 PTE-ET colocalizes with mitochondria in HeLa cells. Cells were incubated with $10 \mu \mathrm{M}$ phenyltetraene analog of edelfosine (PTE-ET, blue fluorescence) for the indicated times, and the location of mitochondria was examined using MitoTracker (MIT, red fluorescence). Areas of colocalization between PTE-ET and mitochondria in the PTE-ET + MIT panels are purple. The corresponding differential interference contrast (DIC) images are also shown. Images are representative of three independent experiments. Bar, $20 \mu \mathrm{m}$

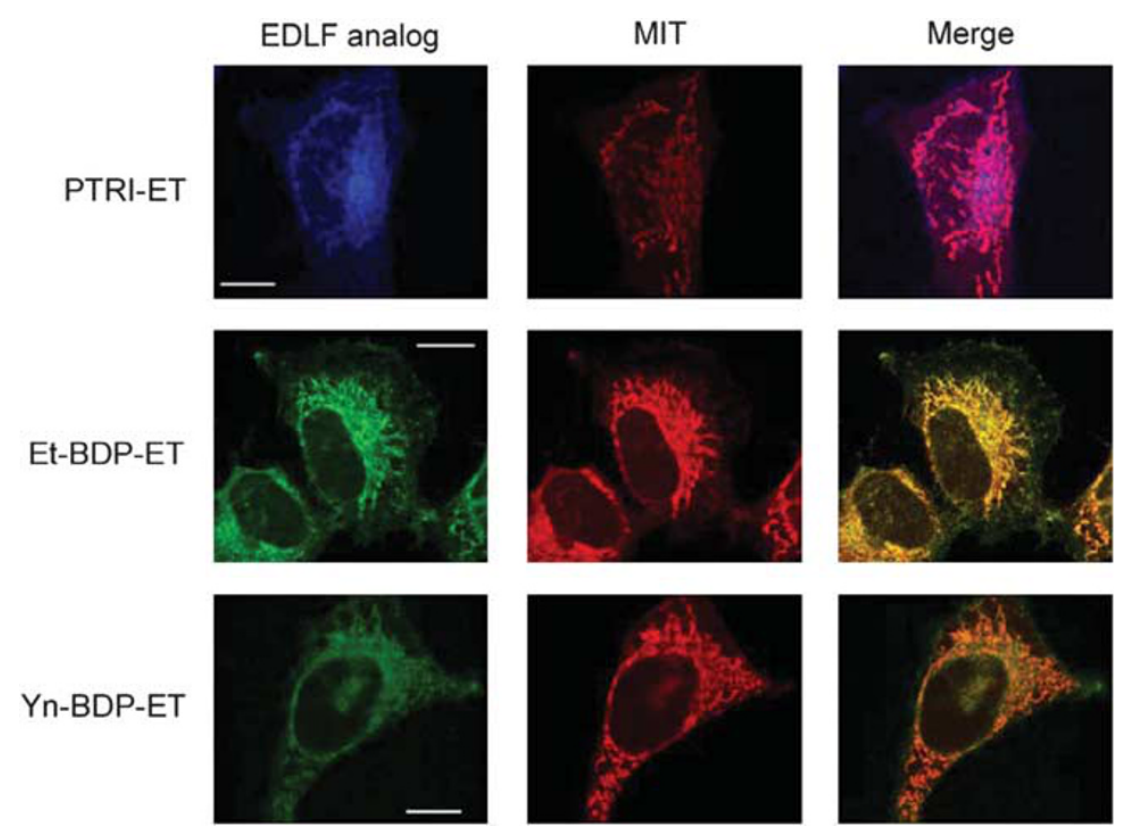

Figure 5 Newly synthesized edelfosine fluorescent analogs colocalize with mitochondria. HeLa cells were incubated for $12 \mathrm{~h}$ with $10 \mu \mathrm{M}$ of the edelfosine (EDLF) fluorescent analogs PTRI-ET (blue fluorescence), Et-BDP-ET (green fluorescence) and Yn-BDP-ET (green fluorescence) to visualize drug (EDLF analog) subcellular localization. Mitochondria location was examined using MitoTracker (MIT, red fluorescence). Areas of colocalization between edelfosine analogs and mitochondria in the merge panels are purple (for PTRI-ET) or yellow (for Et-BDP-ET and Yn-BDP-ET). Images are representative of three independent experiments. Bar, $10 \mu \mathrm{m}$

decrease in the absorbance at $540 \mathrm{~nm} .^{20}$ Exposure of mitochondria to edelfosine $(5-50 \mu \mathrm{M})$ induced a rapid loss of absorbance, indicating mitochondrial swelling (Figures $6 \mathrm{a}$ and $b$ ). Total decrease in absorbance following exposure to edelfosine $50 \mu \mathrm{M}$ was $26.7 \pm 0.1 \%(n=6)$. This effect of edelfosine on mitochondrial swelling was dependent on its ether lipid molecular structure, as an structurally related inactive analog, ET-18-OH (1-O-octadecyl-rac-glycero-3phosphocholine; Figure 2), in which the methoxy group in the $s n-2$ position was replaced by an $\mathrm{OH}$ group, was unable to induce swelling (Figures 6a and b) and apoptosis. ${ }^{3} \mathrm{We}$ next examined the effect of cyclosporin A (CsA), which has been reported to prevent $\Delta \Psi_{\mathrm{m}}$ disruption, and it is considered as a prototypical inhibitor of the mitochondrial PTP. ${ }^{21}$ We found that CsA partially inhibited mitochondrial swelling induced by edelfosine $(10 \mu \mathrm{M})$ in isolated mitochondria (Figure 6c). We also found that CsA $(10 \mu \mathrm{M})$ failed to inhibit this response to higher doses of edelfosine and in long-term experiments (data not shown). This finding is in agreement with previous studies reporting that the pharmacological effects of CsA on mitochondrial PTP, which prevent apoptosis-associated $\Delta \Psi_{\mathrm{m}}$ loss, are transitory. ${ }^{22}$ Taken together, these data indicate that edelfosine induces mitochondrial swelling in a concentration-dependent manner, and therefore edelfosine is able to affect directly mitochondria in a way that might promote cancer cell death. 

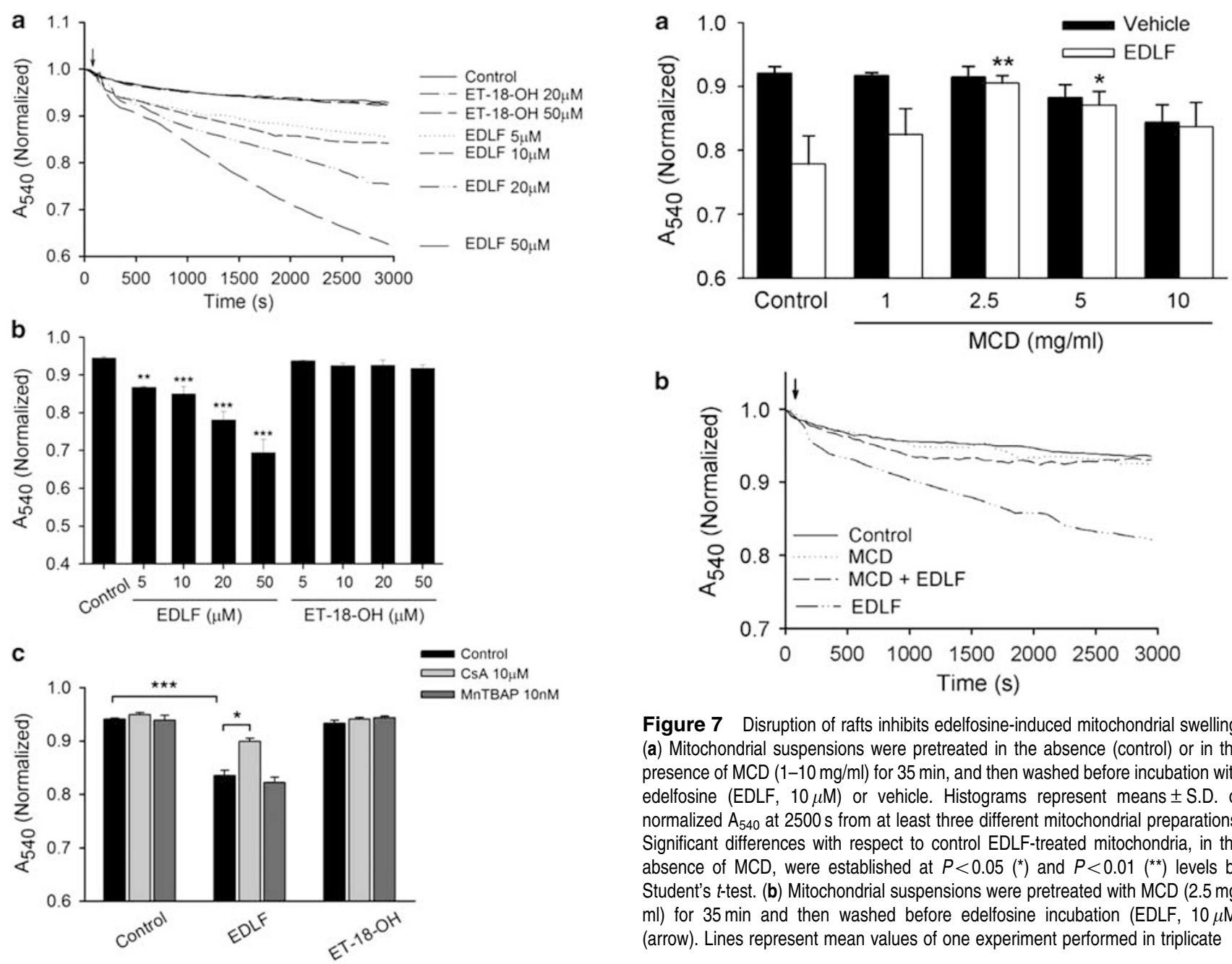

b

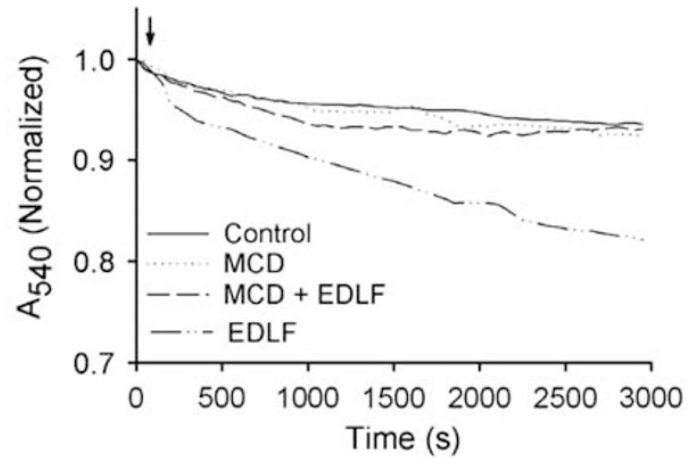

Figure 7 Disruption of rafts inhibits edelfosine-induced mitochondrial swelling. (a) Mitochondrial suspensions were pretreated in the absence (control) or in the presence of $M C D(1-10 \mathrm{mg} / \mathrm{ml})$ for $35 \mathrm{~min}$, and then washed before incubation with edelfosine $(E D L F, 10 \mu \mathrm{M})$ or vehicle. Histograms represent means \pm S.D. of normalized $A_{540}$ at $2500 \mathrm{~s}$ from at least three different mitochondrial preparations. Significant differences with respect to control EDLF-treated mitochondria, in the absence of MCD, were established at $P<0.05\left(^{*}\right)$ and $P<0.01\left(^{* *}\right)$ levels by Student's t-test. (b) Mitochondrial suspensions were pretreated with MCD $(2.5 \mathrm{mg} /$ $\mathrm{ml}$ ) for $35 \mathrm{~min}$ and then washed before edelfosine incubation (EDLF, $10 \mu \mathrm{M}$ ) (arrow). Lines represent mean values of one experiment performed in triplicate

Figure 6 Edelfosine induces mitochondrial swelling. (a) Mitochondrial suspensions were incubated in the absence (control) or in the presence of edelfosine (EDLF, 5-50 $\mu \mathrm{M}$ ) or of the structurally related, but inactive, edelfosine analog ET$18-\mathrm{OH}(20-50 \mu \mathrm{M})$. Edelfosine induces mitochondrial swelling in liver-isolated mitochondria. Lines represent mean values of one experiment performed in triplicate. (b) Histograms represent means \pm S.D. of normalized $A_{540}$ at $2500 \mathrm{~s}$ from at least six different mitochondrial preparations. (c) Effect of CsA and free radical scavenger MnTBAP on the mitochondrial swelling induced by edelfosine. Mitochondrial suspensions were preincubated with CsA $(10 \mu \mathrm{M})$ or MnTBAP $(10 \mathrm{nM})$ for $25 \mathrm{~min}$ before edelfosine $(10 \mu \mathrm{M})$ addition (arrow in a). Data shown are means \pm S.D. of normalized $A_{540}$ at $2500 \mathrm{~s}$ from at least three different mitochondrial preparations. Significant differences with respect to untreated mitochondria were established at $P<0.05\left(^{*}\right), P<0.01{ }^{(*)}$ and $P<0.001\left(^{* \star *}\right.$ levels by Student's $t$-test

We have previously shown that edelfosine induced $\Delta \Psi_{\mathrm{m}}$ disruption, followed by production of reactive oxygen species (ROS) in leukemic cells. ${ }^{18}$ To analyze whether ROS, produced by the action of edelfosine on mitochondria, were involved in edelfosine-induced mitochondrial swelling, we tested the effect of free radical scavengers. As shown in Figure 6c, Mn(III)tetrakis (4-benzoic acid) porphyrin (MnTBAP), a non-peptidyl mimic of superoxide dismutase, did not affect edelfosine-induced mitochondrial swelling, suggesting that ROS do not contribute to edelfosine-induced mitochondrial swelling.

Edelfosine-induced swelling in mitochondria is mediated by lipid rafts. As edelfosine accumulates in rafts $^{9-12,23}$ and we have found here that it also interacts with mitochondria, we wondered whether cholesterol-rich membrane domains could participate in the herein reported edelfosine-promoted changes in isolated mitochondria. As shown in (Figures $7 a$ and $b$ ), disruption of membrane rafts with the cholesterol-depleting agent MCD $^{14,17,19}$ inhibited mitochondrial swelling induced by edelfosine $(10 \mu \mathrm{M})$ in isolated mitochondria. A concentration-dependent effect of MCD on edelfosine-induced mitochondrial swelling was observed (Figure 7a). MCD pretreatment, at concentrations of $2.5-5.0 \mathrm{mg} / \mathrm{ml}$, previously shown to deplete cholesterol, ${ }^{19}$ significantly inhibited edelfosine-induced mitochondrial swelling (Figure 7a). Thus, the action of edelfosine on isolated mitochondria was dependent on rafts present in these organelles. MCD, when used at higher concentrations $(10 \mathrm{mg} / \mathrm{ml})$, compromised mitochondria, as it caused a direct effect on mitochondrial swelling, even in the absence of edelfosine (Figure 7a).

Colocalization of lipid rafts with mitochondria upon edelfosine treatment. As both radioactive edelfosine and its fluorescent analog PTE-ET have been shown to accumulate 
HeLa
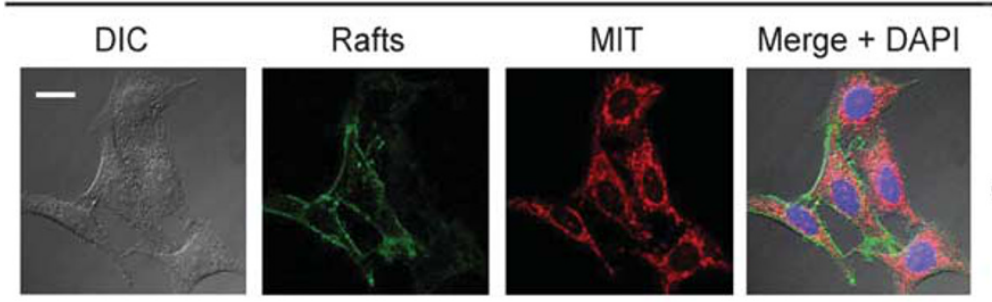

Control
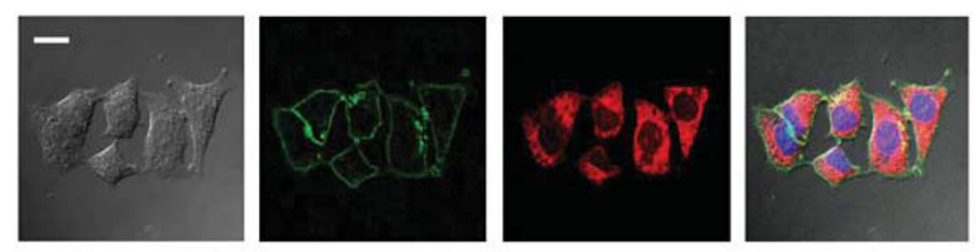

EDLF 6h
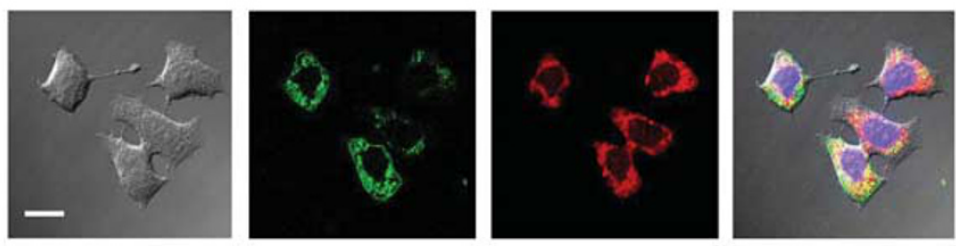

EDLF 8h
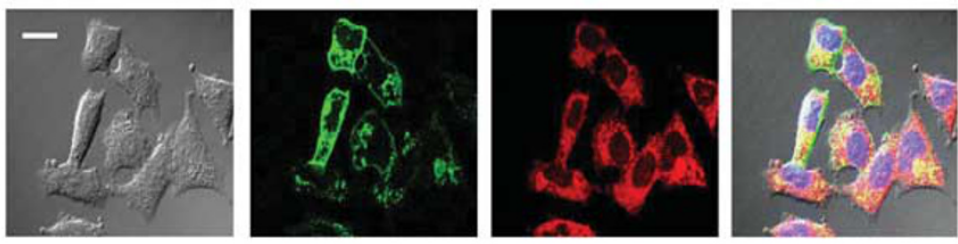

EDLF $17 \mathrm{~h}$
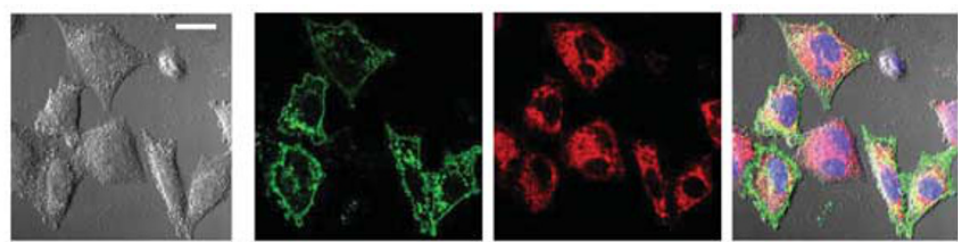

EDLF $24 \mathrm{~h}$

Figure 8 Colocalization of lipid rafts and mitochondria following edelfosine treatment. HeLa cells were untreated (control) or treated with $10 \mu \mathrm{M}$ edelfosine (EDLF) for the indicated times. Rafts, identified by using FITC-CTx B subunit (rafts, green fluorescence), and mitochondria, identified by using MitoTracker (MIT, red fluorescence), were visualized by confocal microscopy. Areas of colocalization between rafts and mitochondria in the merge panels are yellow. The corresponding differential interference contrast (DIC) microscopy images are also shown. Nuclei were stained with DAPI (4',6-diamidino-2-phenylindole) blue fluorescent dye. Bar, $20 \mu \mathrm{m}$

in cholesterol-rich lipid rafts ${ }^{9-12,23}$ and mitochondria are cholesterol-poor organelles containing only $0.5-3 \%$ of the sterol found in plasma membrane, ${ }^{24}$ we hypothesized whether edelfosine treatment led to a redistribution of lipid rafts into the tumor cell. Rafts were visualized through confocal microscopy, by using the raft marker fluorescein isothiocyanate (FITC)-cholera toxin (CTx) B subunit that binds ganglioside GM1, mainly found in these domains, ${ }^{14}$ whereas mitochondria were visualized by using MitoTracker as above. As shown in Figure 8, rafts were mainly located at the plasma membrane in untreated HeLa cells, whereas mitochondria were observed as a widespread network in the interior of the cell. After a 6-h incubation time, rafts largely remained at the cell surface (Figure 8). Following edelfosine treatment, rafts were gradually internalized into the cell, whereas mitochondria clustered around the nuclei, leading to a more intense fluorescent signal. After 8-h incubation time, a fraction of rafts were internalized, showing colocalization with mitochondria (Figure 8). At later incubation times (17-h incubation), a high proportion of rafts were already found in the interior of the cell, colocalizing with clusters of mitochondria that surrounded the nuclei (Figure 8). These changes occurred almost simultaneously with the onset of apoptosis in HeLa cells, which took place after 12-24h incubation with edelfosine (Figure 1). Following 24-h drug treatment, when cells underwent apoptosis, the characteristic blebbing was observed with blebs enriched in rafts (Figure 8). These data suggest that rafts are redistributed in the tumor cell upon edelfosine treatment and eventually interact with mitochondria. Our data unveil a link between plasma membrane rafts and mitochondria driven by edelfosine, and also suggest that cholesterol-rich lipid rafts may have a role in mitochondrial-mediated processes in cancer chemotherapy. 


\section{Discussion}

Lipid rafts and mitochondria show promise as targets in cancer therapy because of their role in regulating apoptosis. Here, through the synthesis of a number of fluorescent edelfosine analogs that preserved the proapoptotic features of the parent drug, we have found for the first time that an alkyllysophospholipid analog colocalizes with mitochondria, and that edelfosine affects mitochondria in a direct way. This effect of edelfosine on mitochondria was dependent on lipid rafts. In addition, treatment of cancer cells with edelfosine induced the redistribution of rafts from plasma membrane to mitochondria, involving a raft-mediated link between plasma membrane and mitochondria. This interaction between edelfosine and mitochondria might explain the involvement of mitochondria in edelfosine-mediated apoptosis, ${ }^{3,17,18}$ and could provide an insight on the role of lipid rafts in cancer chemotherapy and mitochondrial-mediated apoptosis.

The interaction between edelfosine and mitochondria might underlie the antitumor action of this ether phospholipid. We have found here that disruption of rafts by cholesterol depletion with MCD inhibited the mitochondrial swelling induced by edelfosine. In this regard, it is worth to note that edelfosine accumulates in rafts, ${ }^{9-12,23}$ which might be explained, at least in part, by the high affinity of edelfosine for cholesterol, ${ }^{7,8}$ because of geometry compensation of the 'cone shape' of sterols and the 'inverted cone shape' of edelfosine that leads to a stable bilayer. ${ }^{8}$ Taken together, these findings suggest the presence of cholesterol-containing raft-like microdomains in mitochondria and their involvement in edelfosine-induced effects on mitochondria.

The existence of raft-like domains in mitochondria is a controversial issue, but increasing evidence supports their presence. ${ }^{25,26}$ Raft-like domains enriched in ganglioside GD3 and containing voltage-dependent anion channel protein 1 have been detected in mitochondria. ${ }^{27}$ These mitochondrial raft-like domains may represent preferential sites where specific key processes leading to apoptosis take place, as raft disruption in isolated mitochondria prevented edelfosineinduced swelling (this work) and mitochondrial depolarization induced by GD3 or tBid. ${ }^{27}$ In this regard, the mitochondrial pore-forming complex has been shown to contain cholesterol, ${ }^{28}$ and an appropriate level of cholesterol in mitochondrial raft-like microdomains is crucial for the proper function of mitochondria during apoptosis. ${ }^{27}$ Cholesterol depletion by MCD treatment has been recently shown to impair mitochondrial bioenergetics and to decrease calcium chloride-induced swelling. ${ }^{29}$ In rat liver mitochondria, cholesterol has been shown to be mainly distributed within the outer membrane, involved in the creation of mitochondria contact sites, ${ }^{30}$ joining mitochondrial membranes, where members of the PTP complex, such as the voltage-dependent anion channel, are localized in cholesterol-containing lipid raft-like areas. ${ }^{31}$

The plasma membrane contains about $60-80 \%$ of total cellular cholesterol, and it has been estimated that cholesterol is as much as $30-40 \%$ of the lipid molecules in the plasma membrane. $^{32}$ In contrast, mitochondria are considered cholesterol-poor organelles, with estimates ranging from $0.5-3 \%$ of the content found in plasma membrane. ${ }^{24}$ Interestingly, larger amounts of mitochondrial cholesterol have been found in solid tumors. Mitochondrial cholesterol levels in rat and human hepatoma cells were 3- to 10-fold higher than in normal rat and human liver mitochondria. ${ }^{33,34}$ Elevated mitochondrial cholesterol levels have been found to be associated with tumor growth and malignancy, and contribute to chemotherapy resistance. ${ }^{34}$ Our previous ${ }^{12}$ and present results indicate that this resistance seems to be overcome by edelfosine, and the presence of rafts in mitochondria would indeed facilitate the apoptotic action of this ether phospholipid, likely, through its affinity for cholesterol. ${ }^{7,8}$ Recently, we have shown in vitro and in vivo evidence for the involvement of tumor cell cholesterol and rafts in the antitumor action of edelfosine. ${ }^{12,17,35}$ In addition, our present findings suggest that edelfosine promotes colocalization of rafts and mitochondria, suggesting that this ether phospholipid induces internalization of rafts, or at least some of their components, into mitochondria. In this regard, edelfosine has been found to redistribute ergosterol from the plasma membrane into the cell in Saccharomyces cerevisiae yeasts. ${ }^{13}$ Preliminary data suggest that cholesterol is internalized in HeLa cells following edelfosine treatment, with a concomitant increase in the mitochondrial cholesterol level (Mollinedo F and Gajate C, unpublished observations).

The results reported here suggest that edelfosine action involves raft-like microdomains present in both plasma membrane and mitochondria, and that cell surface rafts are internalized to mitochondria following edelfosine treatment. As edelfosine accumulates in rafts, this internalization of cholesterol-containing raft-like microdomains into mitochondria would favor the antitumor action of edelfosine and its location in this organelle. After Fas/CD95 triggering, raft-like microdomains have been detected on mitochondrial membranes, ${ }^{27}$ and edelfosine induces Fas/CD95 triggering in cancer cells. ${ }^{10,11,14,17,36}$ Both vesicular and non-vesicular pathways move sterols between membranes and intracellular compartments, ${ }^{24,32}$ and a raft-modulated non-vesicular transport of sterols from plasma membrane to endoplasmic reticulum has been suggested. ${ }^{37}$

GM1, which is abundant in rafts, has been recently reported to accumulate in the glycosphingolipid-enriched microdomains of mitochondria-associated endoplasmic reticulum membranes, linking endoplasmic reticulum stress to $\mathrm{Ca}^{2+}$. dependent mitochondrial apoptosis. ${ }^{38}$ It is worthy to note that edelfosine-induced apoptosis in HeLa cells has been shown to be mediated by an endoplasmic reticulum stress response, which releases endoplasmic reticulum-stored $\mathrm{Ca}^{2+}$ and requires mitochondria for the apoptotic outcome. ${ }^{16}$ We have previously found that edelfosine was mainly located in endoplasmic reticulum in solid tumor cells. ${ }^{15}$ Physical interaction between endoplasmic reticulum and mitochondria ${ }^{39}$ could underlie this dual location of edelfosine in both endoplasmic reticulum and mitochondria.

Our present results suggest a lipid raft interplay between the cell surface and mitochondria, which might have a critical role in the modulation of apoptosis, and therefore it may have important clinical implications. How lipid rafts are involved in this process remains to be elucidated. Here, we have found that edelfosine affects directly mitochondria in a raft-dependent way that would eventually lead to apoptosis. Our results unveil new insights into the mechanism of action of 
alkyl-lysophospholipid analogs and into the role of rafts in mitochondria and apoptosis, thus opening new avenues for cancer treatment.

\section{Materials and Methods}

Drugs and reagents. Edelfosine was from Apointech (Salamanca, Spain), and stock solutions were prepared, as described previously. ${ }^{3}$ Edelfosine analog $\mathrm{ET}-18-\mathrm{OH}{ }^{3}$ was provided by M Modolell (Max-Planck-Institut für Immunbiologie, Freiburg, Germany). Cyclosporin (CsA) and MCD were from Sigma (St. Louis, MO, USA). MnTBAP was purchased from Calbiochem (San Diego, CA, USA).

Cell culture and $b c l-x_{L}$ transfection. HeLa cells were grown in DMEM culture medium supplemented with $10 \%(\mathrm{v} / \mathrm{v})$ heat-inactivated fetal bovine serum, $2 \mathrm{mM} \mathrm{L}$-glutamine, $100 \mathrm{units} / \mathrm{ml}$ penicillin and $100 \mu \mathrm{g} / \mathrm{ml}$ streptomycin at $37^{\circ} \mathrm{C}$ in $5 \%$ $\mathrm{CO}_{2}$ humidified air. Cells were periodically tested for Mycoplasma infection and found negative. HeLa cells were transfected with pSFFV-neo expression vector containing the human $b c l-x_{L}$ open reading frame, driven by the long terminal repeat of the splenic focus-forming virus (pSFFV-Bcl- $\mathrm{x}_{\mathrm{L}}$ ), as previously described. ${ }^{3,16}$ As a control, transfection was performed with empty PSFFV-neo plasmid. Transfected clones were selected by growth in the presence of $600 \mu \mathrm{g} / \mathrm{ml}$ of G418 (Sigma) and monitored by western blotting using the $2 \mathrm{H} 12$ anti-29 kDa Bcl- $\mathrm{x}_{\mathrm{L}}$ monoclonal antibody (BD Biosciences PharMingen, San Diego, CA, USA). ${ }^{16}$ HeLa cells transfected with the pSFFV-neo plasmid behaved similarly to wild-type HeLa cells. ${ }^{16}$ HeLa cells expressed endogenous $B c l-x_{L}$, but western blot analysis showed a much higher expression of $\mathrm{Bcl}-\mathrm{x}_{\mathrm{L}}$ protein in $b c l-x_{L}$-transfected HeLa cells. ${ }^{16}$

Synthesis of fluorescent edelfosine analogs. Detailed information on the chemical synthesis and properties of the fluorescent edelfosine analogs is included in Supplementary Information.

Analysis of apoptosis by flow cytometry. Quantitation of apoptotic cells was determined by flow cytometry as the percentage of cells in the sub- $\mathrm{G}_{1}$ region (hypodiploidy) in cell cycle analysis, as previously described. ${ }^{36}$

Cytofluorimetric analysis of $\Delta \boldsymbol{\Psi}_{\mathrm{m}}$. To evaluate the $\Delta \Psi_{\mathrm{m}}$, cells were incubated in PBS with $20 \mathrm{nM} 3,3^{\prime}$-DiOC6(3) (green fluorescence; Molecular Probes, Leiden, the Netherlands) for $20 \mathrm{~min}$ at $37^{\circ} \mathrm{C}$, followed by analysis on a FACScan cytofluorimeter, as previously described. ${ }^{18}$

Fluorescence microscopy. Cells were incubated with the distinct fluorescent edelfosine analogs for the indicated times, and with $100 \mathrm{nM}$ cellpermeant MitoTracker probe (Molecular Probes) for $20 \mathrm{~min}$ to label mitochondria, and then processed and analyzed using a fluorescence microscope (Axioplan 2; Carl Zeiss Microlmaging Inc., Oberkochen, Germany) and a digital camera (ORCAER-1394; Hamamatsu, Hamamatsu City, Japan), as previously described, ${ }^{10}$ or through confocal microscopy using a Zeiss LSM 510 laser scan confocal microscope. ${ }^{14}$ To visualize raft and mitochondria localization, untreated and edelfosine-treated cells were labeled with the raft marker FITC-CTX B subunit, as previously described, ${ }^{14,17}$ and with MitoTracker as above. Then, cells were analyzed with a Zeiss LSM 510 laser scan confocal microscope. Colocalization assays were analyzed by excitation of the corresponding fluorochromes in the same section. Images were viewed and acquired by using a PLAN Apochromat $\times 63 /$ 1.40 NA oil-immersion objective lens and a Zeiss LSM 510 software version 3.5.

Mitochondria isolation for swelling assays. Mitochondria were isolated from the livers of adult Sprague-Dawley rats by standard differential centrifugation, as previously described. ${ }^{40}$ Briefly, tissue was manually homogenized with a Teflon pestle (Selecta, Barcelona, Spain) in solution I containing $230 \mathrm{mM}$ mannitol, $70 \mathrm{mM}$ sucrose, $1 \mathrm{mM}$ EGTA, $2 \mathrm{mM}$ PMSF and $5 \mathrm{mM} \mathrm{HEPES}, \mathrm{pH} 7.4$ on ice. After centrifugation at $4^{\circ} \mathrm{C}(106 \times \mathrm{g}, 80 \mathrm{~s})$, the supernatant was layered onto solution II containing $460 \mathrm{mM}$ mannitol, $140 \mathrm{mM}$ sucrose, $1 \mathrm{mM}$ EGTA, 2 mM PMSF and $10 \mathrm{mM}$ HEPES, pH 7.4 , and centrifuged $(800 \times g, 3 \mathrm{~min})$. The top layer was then centrifuged $(2000 \times g, 5 \mathrm{~min})$, and the mitochondrial pellet resuspended in the experimental buffer containing $215 \mathrm{mM}$ mannitol, $71 \mathrm{mM}$ sucrose, $10 \mathrm{mM}$ succinate and $10 \mathrm{mM} \mathrm{HEPES}, \mathrm{pH} 7.4$, and kept on ice until PTP determinations. Mitochondria were used immediately after preparation. Mitochondrial protein content was quantified by using a BCA protein assay reagent kit (Pierce, Rockford, IL, USA), with bovine serum albumin used as a standard.
Mitochondrial swelling. Mitochondria $(0.7 \mathrm{mg} / \mathrm{ml})$ were incubated in experimental buffer $(215 \mathrm{mM}$ mannitol, $71 \mathrm{mM}$ sucrose, $10 \mathrm{mM}$ succinate and $10 \mathrm{mM}$ HEPES, pH 7.4). The swelling of mitochondria caused by an influx of solutes across the inner membrane was measured by recording the decrease in absorbance at $540 \mathrm{~nm}$ in a spectrophotometer (Bio-Rad, Hercules, CA, USA). Changes in absorbance at $540 \mathrm{~nm}\left(A_{540}\right)$, indicating mitochondrial swelling due to PTP opening, were measured after addition of different compounds.

Cholesterol depletion. To deplete cholesterol, $2.5-3 \times 10^{5} \mathrm{cells} / \mathrm{ml}$ were pretreated with $2.5 \mathrm{mg} / \mathrm{ml} \mathrm{MCD} \mathrm{(Sigma)} \mathrm{for} 35 \mathrm{~min}$ at $37^{\circ} \mathrm{C}$ in serum-free medium. Cells were then washed three times and resuspended in complete culture medium before edelfosine addition, as described. ${ }^{19}$ To deplete cholesterol in mitochondria, a similar method was used with some slight modifications. Mitochondria were incubated with $2.5 \mathrm{mg} / \mathrm{ml} \mathrm{MCD}$ for $35 \mathrm{~min}$ at $4{ }^{\circ} \mathrm{C}$ in experimental buffer $(215$ mannitol, $71 \mathrm{mM}$ sucrose, $10 \mathrm{mM}$ succinate and $10 \mathrm{mM}$ HEPES, pH 7.4), and then washed three times before edelfosine addition.

Statistical analyses. Results given are the mean ( \pm S.D.) of the number of experiments indicated. Statistical evaluation was performed by Student's $t$-test.

\section{Conflict of Interest}

FM is cofounder of Apointech and a member of its scientific advisory board. CG is a member of the scientific advisory board of Apointech. JAVP is an employee of Apointech. The remaining authors declare no conflict of interest.

Acknowledgements. This work was supported by the Spanish Ministerio de Ciencia e Innovación (SAF2008-02251, BQU2003-4413 and RD06/0020/1037 from Red Temática de Investigación Cooperativa en Cáncer, Instituto de Salud Carlos III, cofunded by the Fondo Europeo de Desarrollo Regional of the European Union), Fondo de Investigación Sanitaria and European Commission (FIS-FEDER 06/0813, 08/1434, PS09/01915), European Community's Seventh Framework Programme FP7-2007-2013 (grant HEALTH-F2-2011-256986), Junta de Castilla y León (CSI052A11-2, GR15-Experimental Therapeutics and Translational Oncology Program, Biomedicine Project 2009 and Biomedicine Project 2010-2011), Fundación para la Investigación Sanitaria en Castilla-La Mancha (FISCAM, PI2006/10) and Junta de Comunidades de Castilla-La Mancha (11109-0163-4002). CG is supported by the Ramón y Cajal Program from the Spanish Ministerio de Ciencia e Innovación. MF is recipient of a postdoctoral fellowship from Fondo de Investigación Sanitaria. VH is recipient of a predoctoral fellowship from the Spanish Ministerio de Ciencia e Innovación.

1. Galluzzi L, Larochette N, Zamzami N, Kroemer G. Mitochondria as therapeutic targets for cancer chemotherapy. Oncogene 2006; 25: 4812-4830.

2. Neuzil J, Dyason JC, Freeman R, Dong LF, Prochazka L, Wang XF et al. Mitocans as anticancer agents targeting mitochondria: lessons from studies with vitamin $\mathrm{E}$ analogues, inhibitors of complex II. J Bioenerg Biomembr 2007; 39: 65-72.

3. Mollinedo F, Fernandez-Luna JL, Gajate C, Martin-Martin B, Benito A, Martinez-Dalmau R et al. Selective induction of apoptosis in cancer cells by the ether lipid ET-18-OCH (Edelfosine): molecular structure requirements, cellular uptake, and protection by Bcl-2 and BCl-X. Cancer Res 1997; 57: 1320-1328.

4. Gajate $\mathrm{C}$, Mollinedo $\mathrm{F}$. Biological activities, mechanisms of action and biomedical prospect of the antitumor ether phospholipid ET-18-OCH 3 (Edelfosine), a proapoptotic agent in tumor cells. Curr Drug Metab 2002; 3: 491-525.

5. Mollinedo F, Gajate C, Martin-Santamaria S, Gago F. ET-18- $\mathrm{OCH}_{3}$ (edelfosine): a selective antitumour lipid targeting apoptosis through intracellular activation of Fas/CD95 death receptor. Curr Med Chem 2004; 11: 3163-3184.

6. Mollinedo F. Antitumor ether lipids: proapoptotic agents with multiple therapeutic indications. Expert Opin Ther Patents 2007; 17: 385-405.

7. Ausili A, Torrecillas A, Aranda FJ, Mollinedo F, Gajate C, Corbalan-Garcia $S$ et al. Edelfosine is incorporated into rafts and alters their organization. J Phys Chem B 2008; 112: 11643-11654.

8. Busto JV, del Canto-Jañez E, Goñi FM, Mollinedo F, Alonso A. Combination of the antitumour cell ether lipid edelfosine with sterols abolishes haemolytic side effects of the drug. J Chem Biol 2008; 1: 89-94.

9. van der Luit AH, Budde M, Ruurs P, Verheij M, van Blitterswijk WJ. Alkyl-lysophospholipid accumulates in lipid rafts and induces apoptosis via raft-dependent endocytosis and inhibition of phosphatidylcholine synthesis. J Biol Chem 2002; 277: 39541-39547.

10. Gajate C, Del Canto-Janez E, Acuna AU, Amat-Guerri F, Geijo E, Santos-Beneit AM et al. Intracellular triggering of Fas aggregation and recruitment of apoptotic molecules 
into Fas-enriched rafts in selective tumor cell apoptosis. J Exp Med 2004; 200 353-365

11. Gajate C, Gonzalez-Camacho F, Mollinedo F. Involvement of raft aggregates enriched in Fas/CD95 death-inducing signaling complex in the antileukemic action of edelfosine in Jurkat cells. PLOS ONE 2009; 4: e5044

12. Mollinedo F, de la Iglesia-Vicente J, Gajate C, Estella-Hermoso de Mendoza A, VillaPulgarin JA, Campanero MA et al. Lipid raft-targeted therapy in multiple myeloma Oncogene 2010; 29: 3748-3757.

13. Zaremberg V, Gajate C, Cacharro LM, Mollinedo F, McMaster CR. Cytotoxicity of an anticancer lysophospholipid through selective modification of lipid raft composition. J Biol Chem 2005; 280: 38047-38058.

14. Gajate $\mathrm{C}$, Mollinedo $\mathrm{F}$. The antitumor ether lipid $\mathrm{ET}-18-\mathrm{OCH}_{3}$ induces apoptosis through translocation and capping of Fas/CD95 into membrane rafts in human leukemic cells. Blood 2001; 98: 3860-3863.

15. Nieto-Miguel T, Gajate C, Mollinedo F. Differential targets and subcellular localization of antitumor alkyl-lysophospholipid in leukemic versus solid tumor cells. J Biol Chem 2006 281: $14833-14840$.

16. Nieto-Miguel T, Fonteriz RI, Vay L, Gajate C, Lopez-Hernandez S, Mollinedo F. Endoplasmic reticulum stress in the proapoptotic action of edelfosine in solid tumor cells. Cancer Res 2007; 67: 10368-10378.

17. Gajate C, Mollinedo F. Edelfosine and perifosine induce selective apoptosis in multiple myeloma by recruitment of death receptors and downstream signaling molecules into lipid rafts. Blood 2007; 109: 711-719.

18. Gajate C, Santos-Beneit AM, Macho A, Lazaro M, Hernandez-De Rojas A, Modolell M et al. Involvement of mitochondria and caspase-3 in $\mathrm{ET}-18-\mathrm{OCH}_{3}$-induced apoptosis of human leukemic cells. Int J Cancer 2000; 86: 208-218.

19. Gajate C, Gonzalez-Camacho F, Mollinedo F. Lipid raft connection between extrinsic and intrinsic apoptotic pathways. Biochem Biophys Res Commun 2009; 380: 780-784.

20. Bernardi P, Vassanelli S, Veronese P, Colonna R, Szabo I, Zoratti M. Modulation of the mitochondrial permeability transition pore. Effect of protons and divalent cations. J Biol Chem 1992; 267: 2934-2939.

21. Di Lisa F, Bernardi P. Mitochondrial function as a determinant of recovery or death in cell response to injury. Mol Cell Biochem 1998; 184: 379-391.

22. Zamzami N, Marchetti $P$, Castedo M, Hirsch T, Susin SA, Masse B et al. Inhibitors of permeability transition interfere with the disruption of the mitochondrial transmembrane potential during apoptosis. FEBS Lett 1996; 384: 53-57.

23. Bakht $O$, Delgado J, Amat-Guerri $F$, Acuna AU, London $E$. The phenyltetraene lysophospholipid analog PTE-ET-18-OMe as a fluorescent anisotropy probe of liquid ordered membrane domains (lipid rafts) and ceramide-rich membrane domains. Biochim Biophys Acta 2007; 1768: 2213-2221.

24. Soccio RE, Breslow JL. Intracellular cholesterol transport. Arterioscler Thromb Vasc Bio 2004; 24: 1150-1160.

25. Sorice M, Manganelli V, Matarrese P, Tinari A, Misasi R, Malorni W et al. Cardiolipin enriched raft-like microdomains are essential activating platforms for apoptotic signals on mitochondria. FEBS Lett 2009; 583: 2447-2450.

26. Ciarlo L, Manganelli V, Garofalo T, Matarrese P, Tinari A, Misasi R et al. Association of fission proteins with mitochondrial raft-like domains. Cell Death Differ 2010; 17: 1047-1058.
27. Garofalo T, Giammarioli AM, Misasi R, Tinari A, Manganelli V, Gambardella L et al. Lipid microdomains contribute to apoptosis-associated modifications of mitochondria in T cells. Cell Death Differ 2005; 12: 1378-1389.

28. De Pinto V, Benz R, Palmieri F. Interaction of non-classical detergents with the mitochondrial porin. A new purification procedure and characterization of the pore-forming unit. Eur J Biochem 1989; 183: 179-187.

29. Ziolkowski W, Szkatula M, Nurczyk A, Wakabayashi T, Kaczor JJ, Olek RA et al. Methylbeta-cyclodextrin induces mitochondrial cholesterol depletion and alters the mitochondrial structure and bioenergetics. FEBS Lett 2010; 584: 4606-4610.

30. Ardail D, Privat JP, Egret-Charlier M, Levrat C, Lerme F, Louisot P. Mitochondrial contact sites. Lipid composition and dynamics. J Biol Chem 1990; 265: 18797-18802.

31. Grimm S, Brdiczka D. The permeability transition pore in cell death. Apoptosis 2007; 12: 841-855.

32. Maxfield FR, Wustner D. Intracellular cholesterol transport. J Clin Invest 2002; 110: 891-898.

33. Crain RC, Clark RW, Harvey BE. Role of lipid transfer proteins in the abnormal lipid content of Morris hepatoma mitochondria and microsomes. Cancer Res 1983; 43: 3197-3202.

34. Montero J, Morales A, Llacuna L, Lluis JM, Terrones O, Basanez G et al. Mitochondrial cholesterol contributes to chemotherapy resistance in hepatocellular carcinoma. Cancer Res 2008; 68: 5246-5256.

35. Mollinedo F, de la Iglesia-Vicente J, Gajate C, Estella-Hermoso de Mendoza A, VillaPulgarin JA, de Frias $\mathrm{M}$ et al. In vitro and in vivo selective antitumor activity of Edelfosine against mantle cell lymphoma and chronic lymphocytic leukemia involving lipid rafts. Clin Cancer Res 2010; 16: 2046-2054.

36. Gajate C, Fonteriz RI, Cabaner C, Alvarez-Noves G, Alvarez-Rodriguez Y, Modolell M et al. Intracellular triggering of Fas, independently of FasL, as a new mechanism of antitumor ether lipid-induced apoptosis. Int J Cancer 2000; 85: 674-682.

37. Li Y, Prinz WA. ATP-binding cassette (ABC) transporters mediate nonvesicular, raftmodulated sterol movement from the plasma membrane to the endoplasmic reticulum. J Biol Chem 2004; 279: 45226-45234.

38. Sano R, Annunziata I, Patterson A, Moshiach S, Gomero E, Opferman J et al. GM1ganglioside accumulation at the mitochondria-associated ER membranes links ER stress to $\mathrm{Ca}^{2+}$-dependent mitochondrial apoptosis. Mol Cell 2009; 36: 500-511.

39. de Brito OM, Scorrano L. Mitofusin 2 tethers endoplasmic reticulum to mitochondria. Nature 2008; 456: 605-610.

40. Jordan J, Galindo MF, Tornero D, Benavides A, Gonzalez C, Agapito MT et al. Superoxide anions mediate veratridine-induced cytochrome $c$ release and caspase activity in bovine chromaffin cells. Br J Pharmacol 2002; 137: 993-1000.

Cell Death and Disease is an open-access journal published by Nature Publishing Group. This work is licensed under the Creative Commons Attribution-Noncommercial-No Derivative Works 3.0 Unported License. To view a copy of this license, visit http://creativecommons.org/licenses/by-nc-nd/3.0/

Supplementary Information accompanies the paper on Cell Death and Disease website (http://www.nature.com/cddis) 